\title{
Bupivacaine causes cytotoxicity in mouse C2C12 myoblast cells: involvement of ERK and Akt signaling pathways
}

\author{
Joseph M MAURICE ${ }^{1,2}$, Yan GAN ${ }^{1}$, Fan-xin MA $^{1}$, Yong-chang $\mathrm{CHANG}^{3}$, Michael HIBNER ${ }^{1}$, Yao HUANG ${ }^{1, *}$ \\ ${ }^{1}$ Department of Obstetrics and Gynecology, St Joseph's Hospital and Medical Center, Phoenix, AZ, USA; ${ }^{2}$ Department of Obstetrics and \\ Gynecology, Rush University Medical Center, Chicago, IL, USA; ${ }^{3}$ Barrow Neurological Institute, St Joseph's Hospital and Medical Center, \\ Phoenix, AZ, USA
}

\begin{abstract}
Aim: The adverse effects of local anesthetics (LAs) on wound healing at surgical sites have been suggested, and may be related to their cytotoxicity. This study was aimed to compare the cellular toxicity of bupivacaine and lidocaine (two well-known LAs), and to explore the molecular mechanism(s).

Methods: Toxicity of bupivacaine and lidocaine was assessed in cultured mouse C2C12 myoblasts by cell viability and apoptosis assays. Effects of LAs on extracellular signal-regulated kinase (ERK) and protein kinase B (Akt) activation, which are essential for cell proliferation and survival, were evaluated by immunoblotting.

Results: Both LAs, especially bupivacaine, prevented cell growth and caused cell death in a dose-dependent manner. The half maximal inhibitory concentrations $\left(\mathrm{IC}_{50}\right)$ for bupivacaine and lidocaine were $0.49 \pm 0.04$ and $3.37 \pm 0.53 \mathrm{mmol} / \mathrm{L}$, respectively. When applied at the same dilutions of commercially available preparations, the apoptotic effect induced by bupivacaine was more severe than that of lidocaine in $\mathrm{C} 2 \mathrm{C} 12$ cells. Furthermore, bupivacaine significantly diminished the ERK activation, which may underlie its anti-proliferative actions. Both LAs suppressed Akt activation, which correlated with their effects on apoptosis.

Conclusion: Our study demonstrated that, when used at the same dilutions from clinically relevant concentrations, bupivacaine is more cytotoxic than lidocaine in vitro. Anti-proliferation and cell death with concomitant apoptosis mediated by bupivacaine may offer an explanation for its adverse effects in vivo (eg slowing wound healing at the surgical sites). A less toxic, long-acting anesthetic may be needed.
\end{abstract}

Keywords: local anesthetic; cytotoxicity; cell proliferation; apoptosis; extracellular signal-regulated kinase; Akt

Acta Pharmacologica Sinica (2010) 31: 493-500; doi: 10.1038/aps.2010.20; published online 15 Mar 2010

\section{Introduction}

Local anesthetics (LAs) are widely used to prevent acute, intraoperative, postoperative, and chronic pain. Although LAs are generally accepted as being safe, neurotoxicity and myotoxicity remain considerable concerns. For example, bupivacaine is commonly used to reduce postoperative pain at port sites in patients who undergo laparoscopic surgery. Many patients require quite high doses to relieve their pain ${ }^{[1]}$. Clinical studies have shown that the efficacy of bupivacaine is limited and variable, and in some cases may even prevent

\footnotetext{
* To whom correspondence should be addressed.

E-mail yhuang@chw.edu

Received 2009-11-18 Accepted 2010-01-26

Parts of this work were presented at the 37th and 38th Global Congresses of Minimally Invasive Gynecology in Las Vegas, Nevada, USA, 2008, and in Orlando, Florida, USA, 2009.
}

or slow the wound healing at the surgical sites ${ }^{[2,3]}$. To some extent, the adverse effects on wound healing may be related to the cytotoxicity, as limited studies have suggested that bupivacaine has considerable myotoxicity ${ }^{[4-7]}$.

Although LAs can induce necrotic cell death, apoptosis is believed to be a major cellular suicide mechanism ${ }^{[8,9]}$. In addition, anti-proliferative effects of LAs on human cancer cells have been reported ${ }^{[10,11]}$. Several studies suggest that the LA-induced neurotoxicity may involve mitogen-activated protein kinase (MAPK) and protein kinase B (Akt) signaling pathways ${ }^{[12-15]}$. Compared to neurotoxicity, the molecular mechanisms by which the LAs induce myotoxicity remain poorly understood, although myotoxicity could have severe consequences in clinically relevant settings ${ }^{[16,17]}$.

We hypothesized that bupivacaine has cytotoxic effects via modulation of certain critical cellular signaling pathways. In this study, using mouse $\mathrm{C} 2 \mathrm{C} 12$ myoblasts as a cell model 
system, we assessed the cellular effects of bupivacaine versus lidocaine using a series of cell-based assays and further determined the signaling pathways underlying such effects. Our results may help to design novel strategies aimed to decrease or to minimize the extent of the LA-mediated cytotoxicity.

\section{Materials and methods}

\section{Cell culture and drug treatments}

C2C12 cells (ATCC, Manassas, VA) were routinely cultured in growth medium (GM) consisting of DMEM and $10 \%$ fetal bovine serum (FBS) (Mediatech, Manassas, VA) ${ }^{[18]}$. Bupivacaine and lidocaine (Sigma, St Louis, $\mathrm{MO}$ ) were generally prepared as stocks of $0.5 \%(15.4 \mathrm{mmol} / \mathrm{L})$ and $1 \%(34.6 \mathrm{mmol} / \mathrm{L})$, respectively, in GM with $\mathrm{pH}$ adjusted to 7.4. The cells were pre-seeded at appropriate densities and grown overnight prior to drug treatments. Concentrations of bupivacaine and lidocaine used here were based on previous in vitro studies ${ }^{[19-22]}$, and were also determined by pilot experiments. Lower, subclinical concentrations of both LAs were chosen since their usual clinical preparations (pharmaceutical parental solutions of $0.5 \%$ bupivacaine and $1 \%$ lidocaine) caused immediate cell death in $\mathrm{C} 2 \mathrm{C} 12$ cells (data not shown).

\section{Measurement of cell viability Trypan blue exclusion assay}

Cells were pre-plated at 20000 cells per well in 24-well plates so that they were $\sim 30 \%$ confluent on $\mathrm{d} 0$ when the drug treatments started. The cells were grown in GM in the absence (control) or presence of various concentrations $(0.38,0.51$, and $0.77 \mathrm{mmol} / \mathrm{L}$ ) of bupivacaine over a two-day period. Medium was changed and cells were photographed daily with an inverted microscope (Carl Zeiss, Gottingen, Germany). We chose 24 and $48 \mathrm{~h}$ time points based on previous in vitro studies of LAs ${ }^{[10,13,19]}$. After image acquisition, the cells were trypsinized and stained with trypan blue (Mediatech). Both viable (non-stained) and non-viable (blue) cells were counted using a hemacytometer.

\section{MTT cell proliferation assay}

Cells in triplicates (pre-plated at 4000 cells per well in 96-well plates) were grown in GM with or without bupivacaine or lidocaine (concentrations were specified in each experiment) for $24 \mathrm{~h}$. The yellow tetrazolium MTT was taken up by the cells and then reduced to formazan by intracellular $\mathrm{NAD}(\mathrm{P})$ $\mathrm{H}$-oxidoreductases. The formazan crystals were solubilized and quantified by spectrophotometry. Assays were performed using a MTT Cell Proliferation Kit (Cayman Chemical Co, Ann Arbor, MI) according to the manufacturer's instructions.

\section{Apoptosis/cell death assays}

Apoptosis and necrosis were visualized and quantified using a modified Hoechst 33258 and propidium iodide (PI) double staining $^{[23]}$. Cells were grown in GM with or without bupivacaine or lidocaine for $24 \mathrm{~h}$. Hoechst $33258(5 \mu \mathrm{g} / \mathrm{mL})$ and PI $(15 \mu \mathrm{g} / \mathrm{mL})$ were then added simultaneously and incubated at $37^{\circ} \mathrm{C}$ for an additional $15 \mathrm{~min}$. At the end of the incuba- tion, the cells were washed once with PBS and immediately photographed with a Zeiss inverted fluorescence microscope. Quantification of bright blue (apoptotic), PI-positive/red (late apoptotic and necrotic), and total cells was performed by randomly choosing five fields and counting at least 3000 cells per assay condition using the ImageJ software (developed by W RASBAND, NIH, Bethesda, MD). The cell death rate was expressed as the percentage of apoptotic or necrotic cells from the total cells.

\section{Immunoblotting and densitometry}

C2C12 cells were grown in GM with or without bupivacaine or lidocaine for $24 \mathrm{~h}$. The cells were harvested and lysed in lysis buffer (1\% Triton X-100, $150 \mathrm{mmol} / \mathrm{L} \mathrm{NaCl}, 10 \%$ glycerol, $50 \mathrm{mmol} / \mathrm{L}$ Tris- $\mathrm{HCl}$ (pH 8.0), $100 \mathrm{mmol} / \mathrm{L} \mathrm{NaF}, 2 \mathrm{mmol} / \mathrm{L}$ EDTA) containing protease and phosphatase inhibitors ${ }^{[24]}$. Protein quantification, SDS-PAGE and immunoblotting were performed using our published methods ${ }^{[18]}$. Primary antibodies included anti-activated MAPK (recognizing the dually phosphorylated Thr183 and Tyr185 corresponding to the activated forms of ERK1 and 2) (Promega, Madison, WI) (1:4000), anti-ERK, anti-Akt and anti-phospho-Akt (Thr308) (Cell Signaling, Danvers, MA) (each at 1:1000), and anti- $\beta$ actin (Abcam, Cambridge, MA) (1:5000). Digital images were recorded with Kodak Multimodal Imager 4000MM (Carestream Health, Inc, New Haven, CT) and quantified densitometrically using Kodak Molecular Imaging Software (Version $4.0)$, as described previously ${ }^{[25]}$.

\section{Statistical analysis and determination of $\mathrm{IC}_{50}$}

All statistical data were from multiple experiments or measurements and presented as mean \pm SEM. The significance of differences $(P<0.05)$ was evaluated by one-way ANOVA followed by Bonferroni/Dunnett post hoc test, where appropriate. The half maximal inhibitory concentrations $\left(\mathrm{IC}_{50}\right)$ of the LAs were determined by non-linear least-squares fitting the data of MTT assays using the following equation: Normalized Cell Number $=1 /\left(1+[\mathrm{LA}] / \mathrm{IC}_{50}\right)$, with GraphPad Prism Software (Version 4.0) $)^{[26]}$.

\section{Results}

\section{Bupivacaine causes cytotoxicity in a dose-dependent manner}

To evaluate the cytotoxic effects of bupivacaine, we first assessed cell viability using a well established muscle cell culture model system-mouse $\mathrm{C} 2 \mathrm{C} 12$ myoblasts ${ }^{[18]}$. C2C12 cells were cultured in the absence (control) or presence of various concentrations of bupivacaine over a two-day period. As shown in Figure 1A, control cells grew vigorously and reached confluence on d 2. In contrast, the cell density in the presence of bupivacaine significantly declined in a dose-dependent manner. Notably, a substantial fraction of bupivacaine-treated cells died (cells rounded up and detached), which was mostly evident on d 2. Consistent with the morphological changes, cell growth slowed down and cell death accelerated with the gradual increase in bupivacaine concentration (Figure 1B). Such dose-dependent cytotoxicity was further confirmed by 
A
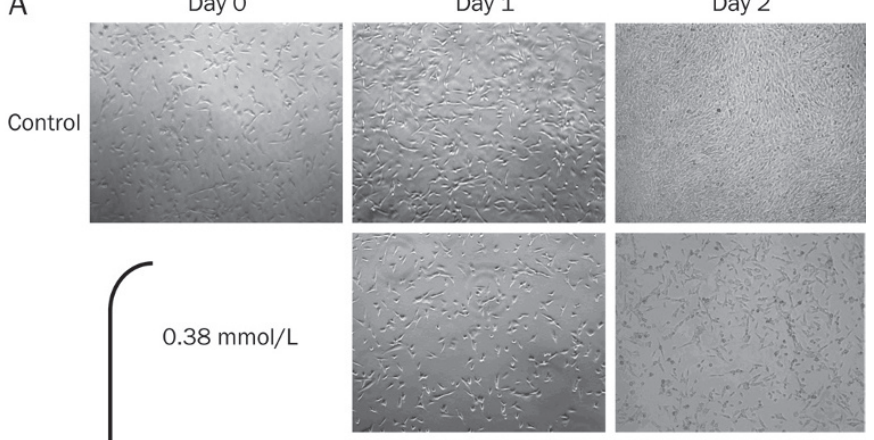

BPV

$0.51 \mathrm{mmol} / \mathrm{L}$
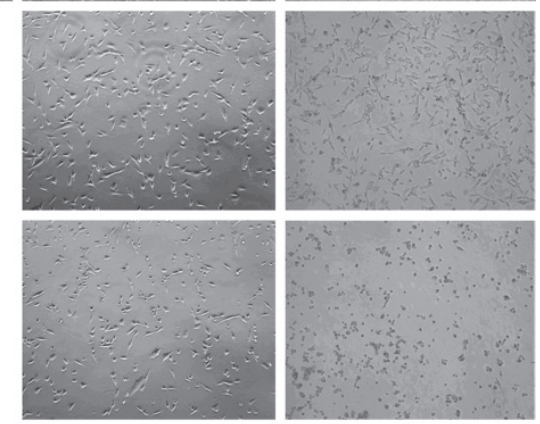

$0.77 \mathrm{mmol} / \mathrm{L}$
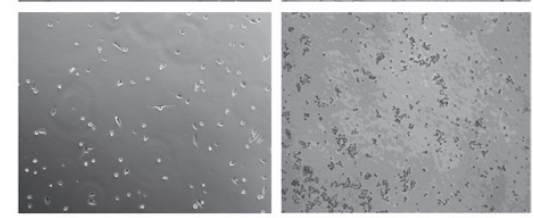

B

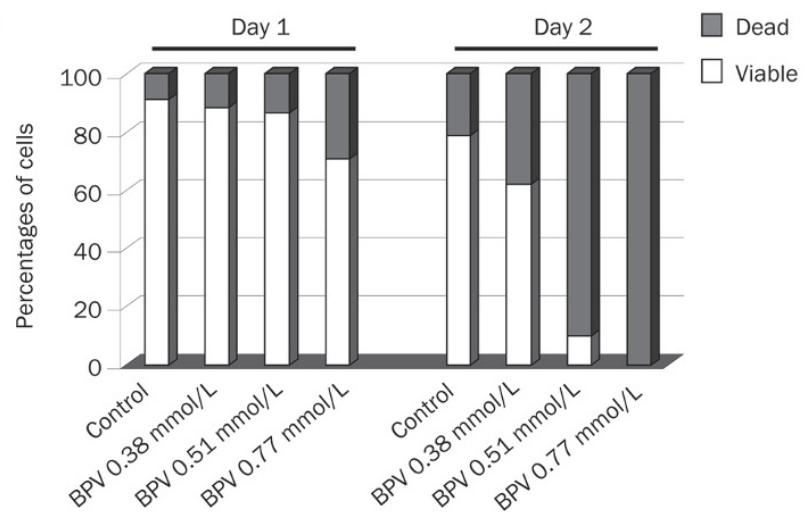

C

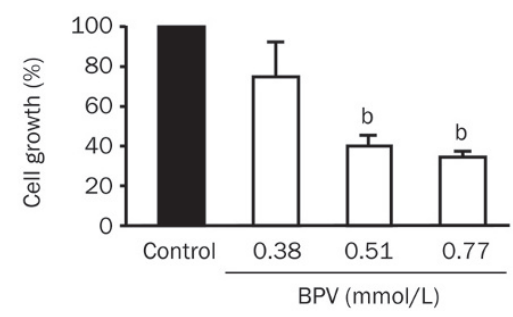

Figure 1. Myotoxicity of bupivacaine in vitro. (A) Representative images of $\mathrm{C} 2 \mathrm{C} 12$ myoblasts cultured in the absence (control) or presence of bupivacaine (BPV) for $0-2 \mathrm{~d}$. (B) Percentages of viable and dead cells from total cells. (C) Dose-dependent inhibition of cell growth. $\mathrm{C} 2 \mathrm{C} 12$ cells were exposed to bupivacaine for $24 \mathrm{~h}$ and then subjected to MTT assays. Cell growth rate (\%) was normalized to the control. Data are mean \pm SEM $(n=3) .{ }^{b} P<0.05$ vs control.

MTT assay (Figure 1C). These data demonstrated that bupivacaine inhibited proliferation and induced cytotoxicity in C2C12 cells.

\section{Bupivacaine is more toxic than lidocaine}

We next performed dose-dependent inhibition curve experiments to compare the pharmacological potency of bupivacaine with another commonly used LA, lidocaine. Our results indicated that $\mathrm{IC}_{50}$ values of bupivacaine and lidocaine were $0.49 \pm 0.04$ and $3.37 \pm 0.53 \mathrm{mmol} / \mathrm{L}$, respectively (Figure 2A). Thus, bupivacaine is approximately 7 -fold more toxic than lidocaine. The common clinical concentrations are $0.25 \%-0.75 \%$ for bupivacaine and $0.5 \%-2 \%$ for lidocaine, which are equivalent to $7.7-23.1 \mathrm{mmol} / \mathrm{L}$ and $17.3-69.2$ $\mathrm{mmol} / \mathrm{L}$, respectively. However, their $\mathrm{IC}_{50}$ values in vivo could be quite different from those determined in vitro. Since clinical concentrations of both LAs caused immediate cell death in $\mathrm{C} 2 \mathrm{C} 12$ culture (data not shown), dilutions from the drug stocks (Figure 2B) were used in this study in an effort to compare their cytotoxicities.

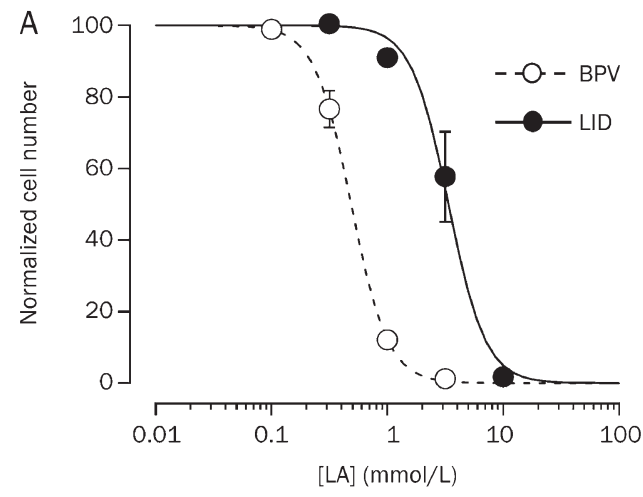

\begin{tabular}{lllll} 
B & \multicolumn{4}{c}{ BPV stock $(0.5 \%=15.4 \mathrm{mmol} / \mathrm{L})$} \\
\cline { 2 - 5 } Dilution & $1: 10$ & $1: 20$ & $1: 30$ & $1: 40$ \\
Dose (mmol/L) & 1.54 & 0.77 & 0.51 & 0.38 \\
& \multicolumn{4}{c}{ LID stock $(1 \%=34.6 \mathrm{mmol} / \mathrm{L})$} \\
\cline { 2 - 5 } Dilution & $1: 10$ & $1: 20$ & $1: 30$ & $1: 40$ \\
Dose (mmol/L) & 3.46 & 1.73 & 1.15 & 0.87
\end{tabular}

Figure 2. Bupivacaine is more toxic than lidocaine in vitro. (A) Dosedependent inhibition curves were determined by MTT assays using a series of concentrations of bupivacaine (BPV) and lidocaine (LID) (0.1, $0.316,1,3.16$, and $10 \mathrm{mmol} / \mathrm{L})$. The $\mathrm{IC}_{50}$ values are $0.49 \pm 0.04 \mathrm{mmol} / \mathrm{L}$ (BPV) and $3.37 \pm 0.53 \mathrm{mmol} / \mathrm{L}(\mathrm{LID})$. Data are mean $\pm \operatorname{SEM}(n=3)$. (B) Conversions between absolute concentrations expressed in Molarity $(\mathrm{mmol} / \mathrm{L})$ and dilution folds of the LA stocks in Percentile (\%).

\section{Bupivacaine induces apoptosis}

We next sought to investigate the molecular mechanism(s) underlying this in vitro toxicity. Apoptosis has been suggested to be one of the mechanisms by which LAs induce cell death ${ }^{[9]}$. Here, we used Hoechst 33258 and PI double staining to assess apoptosis in $\mathrm{C} 2 \mathrm{C} 12$ cells. As shown in Figure 3A, Hoechst stained all nuclei. The apoptotic nuclei exhibited as bright blue due to their nuclear condensation, whereas viable cells were dark blue. Late apoptotic and necrotic cells were stained by PI (red). C2C12 cells were grown in the absence or presence of 

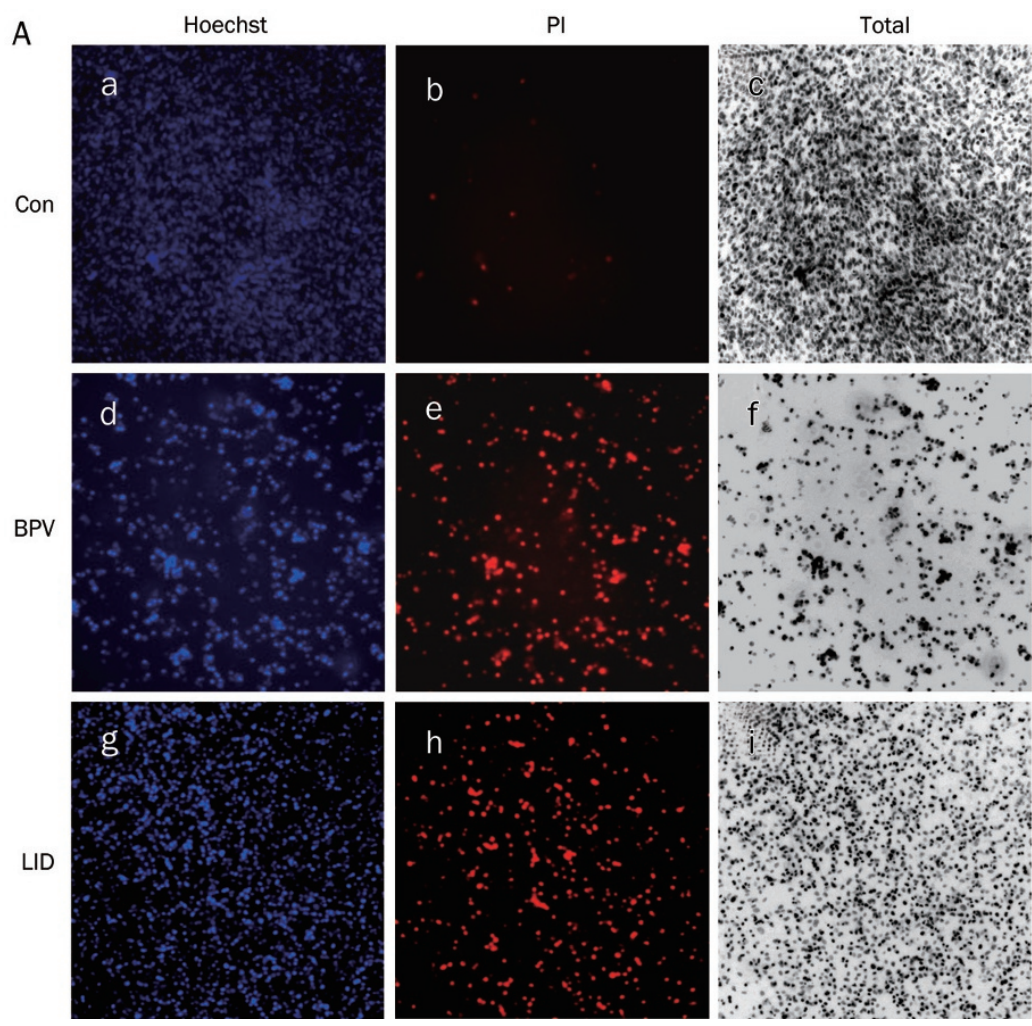

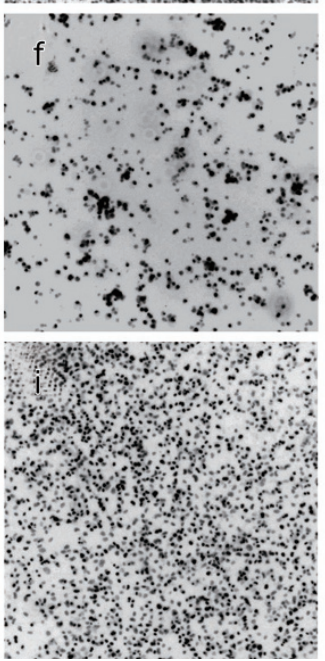

B

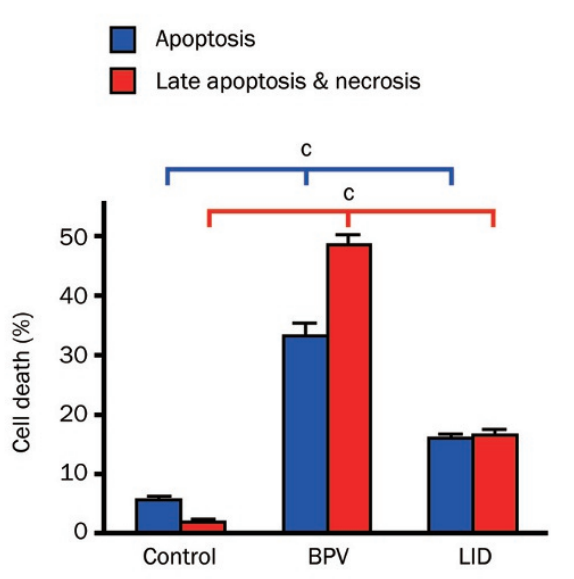

Figure 3. Apoptotic effects of bupivacaine and lidocaine. (A) $\mathrm{C} 2 \mathrm{C} 12$ cells were grown in the absence (control) or presence of bupivacaine or lidocaine (1:20 dilution from 0.5\% BPV and 1\% LID stocks, respectively) for $24 \mathrm{~h}$ and then stained with Hoechst 33258 (a, d, and g) and PI (b, e, and h). Total cells (c, $\mathrm{f}$, and i) were displayed as black and white images converted from Hoechst staining images. Magnification: $\times 100$. (B) Cell death rates were plotted as mean \pm SEM $(n=5)$ of the percentages of bright blue (apoptotic) cells or red (late apoptotic and necrotic) cells from the total cells in the same field as in (A). ${ }^{\mathrm{C}} P<0.01$.

bupivacaine $(0.77 \mathrm{mmol} / \mathrm{L})$ or lidocaine $(1.73 \mathrm{mmol} / \mathrm{L})$ [each equivalent to 1:20 dilution from their respective stocks (Figure 2B)] for $24 \mathrm{~h}$, and then stained with Hoechst (Figure 3A, a, d, and g) and PI (Figure 3A, b, e, and h). For total cell counting purpose, Hoechst staining images were converted to black and white (Figure 3A, c, f, and i). As already observed (Figures 1 and 2), the total cell number in bupivacaine-treated group was significantly less than that in either control or lidocaine-treated group (Figure 3A, f vs c and i). In the control cells, both apoptotic bright blue and necrotic cells were minimal (Figure 3A, $a$ and $b$ ). By contrast, substantial fractions of bupivacaine- or lidocaine-treated cells underwent apoptosis (Figure 3A, d and g) and necrosis (Figure 3A, e and h). Cell death percentages were calculated by normalizing the non-viable cells to the total cells and statistical results are displayed (Figure 3B). Based on these data, we concluded that bupivacaine caused more apoptosis and necrosis (including late apoptosis) than lidocaine did in $\mathrm{C} 2 \mathrm{C} 12$ cells when both LAs were applied at the same dilution (1:20) from clinically relevant concentrations.

\section{Bupivacaine inhibits proliferation via ERK pathway}

Since cellular processes are tightly controlled by the "on and off" of cell signaling pathways, we reasoned that modulation of these pathways could potentially underlie the LA-induced cytotoxicity. It is widely believed that activation of MAPK pathways, in particular the extracellular signal-regulated kinase (ERK) 1 and 2 (p44 and p42 MAPKs), contributes to cell proliferation $^{[27]}$. We previously showed that ERK activation is one of the prerequisites for continuous proliferation of the $\mathrm{C} 2 \mathrm{C} 12$ myoblasts ${ }^{[18]}$. Here we examined the activation status of ERKs by immunoblotting with a specific anti-activated ERK antibody (pERK). In these assays, both bupivacaine and lidocaine were used at a series of concentrations [equivalent to 1:20, 1:30, and 1:40 dilutions from the stocks (Figure 2B)]. As expected, ERKs (mainly p42 MAPK) were robustly activated in control cells (Figure 4A, top, lane 1). Lidocaine did not apparently alter the ERK activation (Figure 4A, top, lanes 2-4 vs 1). However, bupivacaine markedly diminished the ERK activation in a dose-dependent manner (Figure 4A, top, lanes 5-7 vs 1). The total ERK levels were similar under all conditions (Figure $4 \mathrm{~A}$, bottom). As $0.77 \mathrm{mmol} / \mathrm{L}$ (1:20 dilution) was the dosage at which bupivacaine had the most dramatic effect on the ERK activity (Figure 4A, top, lane 5), we performed densitometric analysis of the data obtained from multiple experiments $(n=3)$ at this dilution (Figure $4 \mathrm{~B})$. Bupivacaine treatment reduced the $\mathrm{pERK}$ level to $33.8 \% \pm 6.3 \%(P<0.01)$. In contrast, lidocaine used at the same dilution (1:20) did not significantly differ from the control $(P=0.10)$. These results 


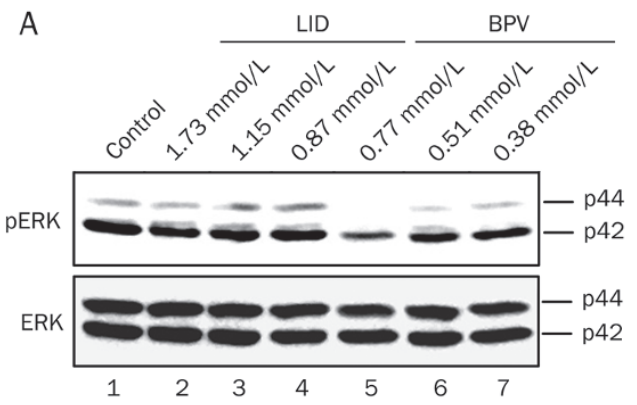

B

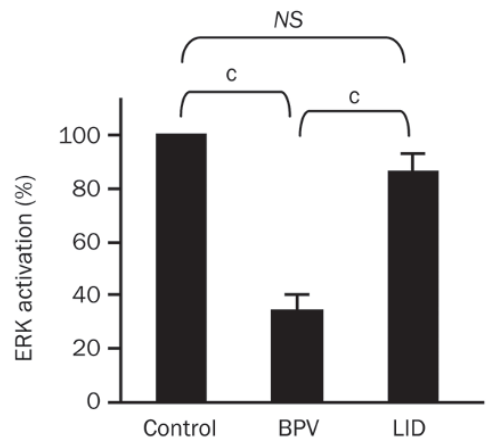

Figure 4. Effects of bupivacaine and lidocaine on ERK (p44/p42 MAPK) activation. (A) $\mathrm{C} 2 \mathrm{C} 12$ cells were grown in the absence (control) or presence of bupivacaine (BPV) or lidocaine (LID) for $24 \mathrm{~h}$ and subjected to immunoblotting with anti-pERK (top panel) and anti-total ERK antibodies (bottom panel), respectively. (B) Densitometric analysis of anti-pERK signals (normalized to total ERK levels) (each LA used at 1:20 dilution) from three independent experiments. Data are relative ERK activation levels with control set as $100 \%$, presented as mean \pm SEM. ${ }^{\circ} P<0.01$; NS, not statistically significant.

suggest that bupivacaine inhibited cell proliferation via the blockade of the ERK pathway.

\section{Bupivacaine induces apoptosis via Akt pathway}

It is known that activation of Akt is critical for cell survival (anti-apoptosis) $^{[28]}$. Here we assessed Akt activation by immunoblotting with an anti-activated Akt antibody (pAkt) in C2C12 cells under the same conditions as described in Figure 4. Akt was robustly activated in the control cells (Figure 5A, top, lane 7). In contrast, bupivacaine suppressed the Akt activation, which was dose-dependent (Figure 5A, top, lanes 1-3). Lidocaine seemed to inhibit the Akt activation only at a higher dose $(1.73 \mathrm{mmol} / \mathrm{L})$ (Figure $5 \mathrm{~A}$, top, lane 4$)$. When we examined the total Akt levels by immunoblotting with an anti-total Akt antibody, we observed a slightly decreased level of total Akt proteins in either bupivacaine- or lidocaine-treated cells compared to the control (Figure 5A, middle, lanes 1-6 vs 7). To exclude the possibility of unequal protein loading, the same blot was reprobed with an anti- $\beta$-actin antibody (Figure $5 \mathrm{~A}$, bottom). The results indicated an equal loading in each lane. Similar to Figure 4B, the degree of Akt activation induced by each treatment regimen (normalized to the total Akt level) was estimated densitometrically from multiple experiments $(n=4)$
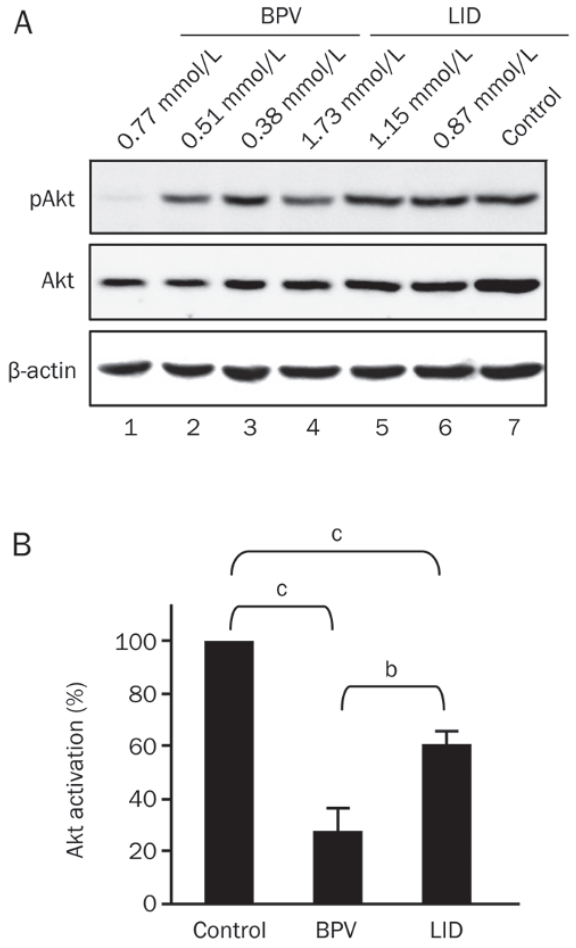

Figure 5. Effects of bupivacaine and lidocaine on Akt activation. (A) $\mathrm{C} 2 \mathrm{C} 12$ cells were grown in the absence (control) or presence of bupivacaine (BPV) or lidocaine (LID) for $24 \mathrm{~h}$ and subjected to immunoblotting with anti-pAkt (top panel), anti-total Akt (middle panel), and anti- $\beta$-actin antibodies (bottom panel), respectively. (B) Densitometric analysis of anti-pAkt signals (normalized to total Akt levels) (each LA used at 1:20 dilution) from four independent experiments. Data are relative Akt activation levels with control set as $100 \%$, presented as mean \pm SEM. ${ }^{\mathrm{b}} P<0.05,{ }^{\mathrm{c}} P<0.01$.

(Figure 5B). Compared to the control, bupivacaine and lidocaine (each used at 1:20 dilution) decreased the Akt activity to $27.4 \% \pm 8.9 \%$ and $60.4 \% \pm 5.1 \%$, respectively. Importantly, bupivacaine was much more potent than lidocaine (approx 2 -fold difference, $P<0.05)$. This largely correlated with the degree of apoptosis under the same conditions (compare Figure 5B with Figure 3B). Taken together, our data suggest that both bupivacaine and lidocaine caused $\mathrm{C} 2 \mathrm{C} 12$ cell apoptosis, at least in part, via inhibiting the Akt activation, and bupivacaine was more toxic than lidocaine in our experimental setting.

\section{Discussion}

The use of bupivacaine and lidocaine in clinical practice is commonplace. The active duration of lidocaine is approximately one half that of bupivacaine, and thus bupivacaine is considered a long-acting LA ${ }^{[29]}$. LAs exhibit variable propensities to induce different cellular damage. For example, both in vitro and in vivo studies have suggested that bupivacaine is less neurotoxic than lidocaine ${ }^{[30,31]}$. Several recent studies revealed that LAs might cause irreversible damage on articular chondrocytes in established experimental models, which may contribute to cartilage degeneration, and lidocaine 
and especially bupivacaine exhibit profound chrondrotoxic effects $^{[21,22,32-34]}$. In contrast, the myotoxic effects of LAs and their clinical consequences have been less studied despite their controversial nature. In one comparison study, the conclusions were that all LAs examined were myotoxic, the extent of muscle damage was dose-dependent and worsened with serial or continuous administration, and that bupivacaine caused the most severe muscle injury ${ }^{[4]}$. Studies on both acute and longterm myotoxic effects of LAs after continuous peripheral nerve blocks in a clinically relevant setting reaffirmed bupivacaine's exceptional rate of myotoxicity ${ }^{[6,7]}$. Excessively increased intracellular $\left[\mathrm{Ca}^{2+}\right]$ level due to an alteration of $\mathrm{Ca}^{2+}$ homeostasis has been suggested as a cause of bupivacaine-induced muscle cell death ${ }^{[35]}$, perhaps mediated by mitochondria ${ }^{[36]}$. However, detailed molecular mechanisms, especially the signaling pathways, by which the LAs exert their cytotoxicities remain to be explored.

In this study, we used a well-established myoblast cell line (C2C12) to demonstrate the direct cytotoxic effects of bupivacaine and, more importantly, to uncover plausible signaling pathways by which bupivacaine causes myotoxicity. We demonstrated that bupivacaine significantly prevented myoblast cell growth and caused cell death in a dose-dependent manner. Apoptosis is an essential cellular process for cell integrity in development and survival. It is also triggered by non-physiological stimulation or insult, leading to pathological conditions. Although apoptosis has been considered as a major mechanism of the LA-induced cell death, especially in the case of neurotoxicity, LAs also lead to necrotic cell death ${ }^{[8,9,37]}$. Our results indicated that both apoptosis and necrosis occurred when C2C12 cells were exposed to bupivacaine or lidocaine; however, bupivacaine was more potent than lidocaine when compared at the same dilution (1:20) from clinically relevant concentrations. In exploring the signaling mechanism, we focused on Akt, as it is a well-acknowledged critical signaling node within the cells under both physiological and pathological conditions and it plays a pivotal role in cell survival ${ }^{[28]}$. We found that Akt activation was decreased in the C2C12 cells cultured in the presence of either bupivacaine or lidocaine. Such inhibition of Akt pathway explains why myoblasts underwent apoptosis upon exposure to bupivacaine or lidocaine, causing massive cell death. Indeed, a negative correlation between the levels of Akt activation and degrees of apoptosis was noted in our current study, which supports the notion that LAs and in particular bupivacaine induce apoptosis via regulation of the Akt pathway. However, we cannot completely rule out that other signaling pathway(s) may also contribute to the LAinduced myotoxicity. It has been shown that both p38 MAPK and c-Jun N-terminal kinase (JNK) pathways are involved in bupivacaine-induced neurotoxicity ${ }^{[13]}$. In rat hippocampal slices, application of millimolar concentrations of lidocaine, but not bupivacaine, resulted in elevated expression of cleaved caspase 3, the primary executioner of apoptosis ${ }^{[38]}$. Active oxidative metabolism involving mitochondrial dysfunction and alterations of $\mathrm{Ca}^{2+}$ homeostasis has been also suggested in bupivacaine-induced myotoxicity ${ }^{[36]}$. These findings raise an interesting possibility that some, if not all, of these pathways could modulate specific LA-induced myotoxicity independently or collaboratively. The other possibility is that different LAs could utilize distinct pathways for myotoxicity and neurotoxicity. Further investigations are needed to address these issues.

MAPK signaling pathways are perhaps among the most wide-spread mechanisms of eukaryotic cell regulation. Multiple MAPK signaling cascades can be activated by a variety of stimuli, allowing the cells to respond coordinately to multiple and divergent inputs ${ }^{[27]}$. The ERK pathway has been believed to be a central regulator of cell proliferation by controlling cell growth and cell cycle progression ${ }^{[27,39]}$. In the muscle cell model system (C2C12), we previously reported that activation of ERKs is one of the prerequisites for continuous myoblast cell growth ${ }^{[18]}$. Here we demonstrated that bupivacaine substantially inhibited the ERK activation in these cells, whereas lidocaine had minimal impact on this mitogenic pathway. This may be one of the molecular mechanisms by which bupivacaine, but not lidocaine, prevented cell growth in vitro. Notably, at a much higher dose $(3.46 \mathrm{mmol} / \mathrm{L})$, lidocaine significantly reduced the total cell numbers (data not shown, also see Figure 2A). This could be a result of cell death induced by this LA, as discussed above. Nevertheless, the differential effects between bupivacaine and lidocaine on cell proliferation raise at least two fundamental questions: What is the molecular basis for these differential actions of LAs? How does bupivacaine inhibit the ERK pathway? A recent study revealed that, in rat spinal cord slices, bupivacaine inhibited the ERK activation resulting from different modes of $\mathrm{Ca}^{2+}$ influx through the cell plasma membrane. This represents a postsynaptic mechanism of analgesia that occurs in parallel with impulse inhibition during neuraxial blockade ${ }^{[40]}$. Whether there exists a similar mechanism in the skeletal muscle cell system remains to be addressed.

Limited clinical studies have suggested that bupivacaine may prevent or slow wound healing at surgical sites ${ }^{[2,3]}$. Our study provides direct supportive evidence that both bupivacaine and lidocaine had myotoxic effects in a myoblast cell culture system. When addressing the differences in cellular effects of the two LAs, bupivacaine was significantly more toxic and, in particular, had a more potent anti-proliferative effect than lidocaine. In this regard, the adverse effect (antiproliferation) itself could turn into advantages in some cases, ie inhibiting cancer cell growth as previously reported ${ }^{[10,11]}$. Although in vitro results obtained here may not exactly mimic the in vivo scenarios, our data at least offer an explanation for bupivacaine's adverse effects on wound healing at surgical sites. It is important to realize that the current study was performed with the utilization of cultured animal cells. The experiment has its limitations, and thus the results may differ from those observed in humans. In vivo and clinical studies would be expected to determine the correlations in the future. However, clinical assessment tools are limited, and currently no effective diagnostic method exists to assess the in vivo cell viability. More often the myotoxicity may not be detected 
until muscle damage or degeneration or other adverse outcomes actually occur in patients. To this end, the in vitro studies have provided useful information, and will assist us with the design of more complex studies using animal models and clinical studies in humans.

Bupivacaine is known to have toxic effects on the nervous and cardiovascular systems as well as articular cartilage and skeletal muscle ${ }^{[17]}$. Thus, the efficacy of LAs may be affected by their toxicities. For example, bupivacaine injected at laparoscopic port sites shows variable effects ${ }^{[1-3]}$. The myotoxicity of bupivacaine demonstrated in this study could contribute to a decreased anesthetic effect and/or slowed wound healing at the surgical sites. It is noteworthy that $\mathrm{N}$-acetylcysteine (NAC), an antioxidant and a precursor of glutathione, can increase cell viability and growth under normal or bupivacaine-treated conditions in cultured rat myoblast L6 cells via modulation of the ERK pathway ${ }^{[41]}$. Thus, combination of a LA with a cellular protective substance may provide another avenue for future studies, which could offer the LA with a better toxicity profile.

\section{Acknowledgements}

This work was supported by a St Joseph's Foundation Startup Fund (to Dr Yao HUANG). Dr Joseph M MAURICE was a recipient of an American Association of Gynecologic Laparoscopy Fellowship.

\section{Author contribution}

Drs Yao HUANG, Michael HIBNER, and Joseph M MAURICE designed the research; Drs Joseph M MAURICE, Yan GAN, and Fan-xin MA performed the experiments; Drs Joseph M MAURICE, Yong-chang CHANG, and Yao HUANG analyzed the data; Drs Yao HUANG and Joseph M MAURICE wrote the article.

\section{References}

1 Malhotra N, Chanana C, Roy KK, Kumar S, Riwari V, Sharma JB. To compare the efficacy of two doses of intraperitoneal bupivacaine for pain relief after operative laparoscopy in gynecology. Arch Gynecol Obstet 2007; 276: 323-6.

2 Fong SY, Pavy TJ, Yeo ST, Paech MJ, Gurrin LC. Assessment of wound infiltration with bupivacaine in women undergoing day-case gynecological laparoscopy. Reg Anesth Pain Med 2001; 26: 131-6.

3 Einarsson JI, Sun J, Orav J, Young AE. Local analgesia in laparoscopy: a randomized trial. Obstet Gynecol 2004; 104: 1335-9.

4 Foster AH, Carlson BM. Myotoxicity of local anesthetics and regeneration of the damaged muscle fibers. Anesth Analg 1980; 59: 727-36.

5 Benoit PW, Belt WD. Destruction and regeneration of skeletal muscle after treatment with a local anaesthetic, bupivacaine (Marcaine). J Anat 1970; 107: 547-56.

6 Zink W, Seif C, Bohl JR, Hacke N, Braun PM, Sinner B, et al. The acute myotoxic effects of bupivacaine and ropivacaine after continuous peripheral nerve blockades. Anesth Analg 2003; 97: 1173-9.

7 Zink W, Bohl JR, Hacke N, Sinner B, Martin E, Graf BM. The long term myotoxic effects of bupivacaine and ropivacaine after continuous peripheral nerve blocks. Anesth Analg 2005; 101: 548-54.

8 Koike T, Tanaka S, Oda1 T, Ninomiya T. Sodium overload through voltage-dependent $\mathrm{Na}^{+}$channels induces necrosis and apoptosis of rat superior cervical ganglion cells in vitro. Brain Res Bull 2000; 51: 345-55.

9 Boselli E, Duflo F, Debon R, Allaouchiche B, Chassard D, Thomas L, et al. The induction of apoptosis by local anesthetics: a comparison between lidocaine and ropivacaine. Anesth Analg 2003; 96: 755-6.

10 Sakaguchi M, Kuroda Y, Hirose M. The antiproliferative effect of lidocaine on human tongue cancer cells with inhibition of the activity of epidermal growth factor receptor. Anesth Analg 2006; 102: 1103-7.

11 Martinsson T. Ropivacaine inhibits serum-induced proliferation of colon adenocarcinoma cells in vitro. J Pharmacol Exp Ther 1999; 288: 660-4.

12 Tan Z, Dohi S, Chen J, Banno Y, Nozawa Y. Involvement of the mitogen-activated protein kinase family in tetracaine-induced PC12 cell death. Anesthesiology 2002; 96: 1191-201.

13 Lirk P, Haller I, Colvin HP, Lang L, Tomaselli B, Klimaschewski L, et al. In vitro, inhibition of mitogen-activated protein kinase pathways protects against bupivacaine- and ropivacaine-induced neurotoxicity. Anesth Analg 2008; 106: 1456-64.

14 Lirk P, Haller I, Colvin HP, Frauscher S, Kirchmair L, Gerner P, et al. In vitro, lidocaine-induced axonal injury is prevented by peripheral inhibition of the p38 mitogen-activated protein kinase, but not by inhibiting caspase activity. Anesth Analg 2007; 105: 1657-64.

15 Lirk P, Haller I, Myers RR, Klimaschewski L, Kau YC, Hung YC, et al. Mitigation of direct neurotoxic effects of lidocaine and amitriptyline by inhibition of p38 mitogen-activated protein kinase in vitro and in vivo. Anesthesiology 2006; 104: 1266-73.

16 Zink W, Graf BM. Local anesthetic myotoxicity. Reg Anesth Pain Med 2004; 29: 333-40.

17 Zink W, Graf BM. The toxicity of local anesthetics: the place of ropivacaine and levobupivacaine. Curr Opin Anaesthesiol 2008; 21: 645-50.

18 Huang Y, Li J, Zhang Y, Wu C. The roles of integrin-linked kinase in the regulation of myogenic differentiation. J Cell Biol 2000; 150: 861-82.

19 Lee HT, Xu H, Siegel CD, Krichevsky IE. Local anesthetics induce human renal cell apoptosis. Am J Nephrol 2003; 23: 129-39.

20 Park CJ, Park SA, Yoon TG, Lee SJ, Yum KW, Kim HJ. Bupivacaine induces apoptosis via ROS in the Schwann cell line. J Dent Res 2005; 84: 852-7.

21 Chu CR, Izzo NJ, Papas NE, Fu FH. In vitro exposure to $0.5 \%$ bupivacaine is cytotoxic to bovine articular chondrocytes. Arthroscopy 2006; 22: 693-9.

22 Karpie JC, Chu CR. Lidocaine exhibits dose- and time-dependent cytotoxic effects on bovine articular chondrocytes in vitro. Am J Sports Med 2007; 35: 1621-7.

23 Clifford JL, Menter DG, Wang M, Lotan R, Lippman SM. Retinoid receptor-dependent and -independent effects of $\mathrm{N}$-(4-hydroxyphenyl) retinamide in F9 embryonal carcinoma cells. Cancer Res 1999; 59: 14-8.

24 Huang Y, Kim SO, Jiang J, Frank SJ. Growth hormone-induced phosphorylation of epidermal growth factor (EGF) receptor in 3T3F442A cells. Modulation of EGF-induced trafficking and signaling. J Biol Chem 2003; 278: 18902-13.

25 Ma F, Zhang D, Yang H, Sun H, Wu W, Gan Y, et al. Endothelial cellspecific molecule 2 (ECSM2) modulates actin remodeling and epidermal growth factor receptor signaling. Genes Cells 2009; 14: 281-93.

26 Huang $\mathrm{Y}$, Chang $\mathrm{Y}$, Wang $\mathrm{X}$, Jiang J, Frank SJ. Growth hormone alters epidermal growth factor receptor binding affinity via activation of ERKs in 3T3-F442A cells. Endocrinology 2004; 145: 3297-306. 
27 Krishna $\mathrm{M}$, Narang $\mathrm{H}$. The complexity of mitogen-activated protein kinases (MAPKs) made simple. Cell Mol Life Sci 2008; 65: 3525-44.

28 Manning BD, Cantley LC. AKT/PKB signaling: navigating downstream. Cell 2007; 129: 1261-74.

29 McLure HA, Rubin AP. Review of local anaesthetic agents. Minerva Anestesiol 2005; 71: 59-74.

30 Radwan IA, Saito S, Goto F. The neurotoxicity of local anesthetics on growing neurons: a comparative study of lidocaine, bupivacaine, mepivacaine, and ropivacaine. Anesth Analg 2002; 94: 319-24.

31 Sakura S, Kirihara Y, Muguruma T, Kishimoto T, Saito Y. The comparative neurotoxicity of intrathecal lidocaine and bupivacaine in rats. Anesth Analg 2005; 101: 541-7.

32 Gomoll AH, Yanke AB, Kang RW, Chubinskaya S, Williams JM, Bach $\mathrm{BR}$, et al. Long-term effects of bupivacaine on cartilage in a rabbit shoulder model. Am J Sports Med 2009; 37: 72-7.

33 Gomoll AH, Kang RW, Williams JM, Bach BR, Cole BJ. Chondrolysis after continuous intra-articular bupivacaine infusion: an experimental model investigating chondrotoxicity in the rabbit shoulder. Arthroscopy 2006; 22: 813-9.

34 Chu CR, Izzo NJ, Coyle CH, Papas NE, Logar A. The in vitro effects of bupivacaine on articular chondrocytes. J Bone Joint Surg Br 2008; 90: 814-20.

35 Benoit PW, Yagiela A, Fort NF. Pharmacologic correlation between local anesthetic-induced myotoxicity and disturbances of intracellular calcium distribution. Toxicol Appl Pharmacol 1980; 52: 187-98.

36 Irwin W, Fontaine E, Agnolucci L, Penzo D, Betto R, Bortolotto S, et al. Bupivacaine myotoxicity is mediated by mitochondria. J Biol Chem 2002; 277: 12221-7.

37 Mukherjee PK, Marcheselli VL, Serhan CN, Bazan NG. Neuroprotectin D1: a docosahexaenoic acid-derived docosatriene protects human retinal pigment epithelial cells from oxidative stress. Proc Natl Acad Sci USA 2004; 101: 8491-6.

38 Dahmani S, Rouelle D, Gressens P, Mantz J. The effects of lidocaine and bupivacaine on protein expression of cleaved caspase 3 and tyrosine phosphorylation in the rat hippocampal slice. Anesth Analg 2007; 104: 119-23.

39 Johnson GL, Lapadat R. Mitogen-activated protein kinase pathways mediated by ERK, JNK, and p38 protein kinases. Science 2002; 298: 1911-2.

40 Yanagidate F, Strichartz GR. Bupivacaine inhibits activation of neuronal spinal extracellular receptor-activated kinase through elective effects on ionotropic receptors. Anesthesiology 2006; 104: 805-14.

41 Kim GH, Song DK, Cho CH, Yoo SK, Kim DK, Park GY, et al. Muscular cell proliferative and protective effects of $\mathrm{N}$-acetylcysteine by modulating activity of extracellular signal-regulated protein kinase. Life Sci 2006; 79: 622-8.

\title{
Future Diagnostics
}

\author{
Irvine, CA, United States \\ 26-27 Apr 2010
}

Organizer: Cambridge Healthtech Institute

Website: www.healthtech.com/dfx?c=7332

Contact: Mr Kris Waterman, 250 First Ave Suite 300 Needham, MA 02494

United States of America; phone: (781-972-5400) 